\title{
Inositol 1,4,5-trisphosphate 3-kinases: functions and regulations
}

\author{
Hui Jun XIA*, Guang YANG \\ Key Laboratory of MOE for Plant Developmental Biology, College of Life Sciences, Wuhan University, Wuhan, Hubei 430072, \\ China
}

\begin{abstract}
Inositol 1,4,5-trisphosphate 3-kinase ( $\mathrm{IP}_{3} 3$-kinase/IP3K) plays an important role in signal transduction in animal cells by phosphorylating inositol 1,4,5-trisphosphate $\left(\mathrm{IP}_{3}\right)$ to inositol 1,3,4,5-tetrakisphosphate $\left(\mathrm{IP}_{4}\right)$. Both $\mathrm{IP}_{3}$ and $\mathrm{IP}_{4}$ are critical second messengers which regulate calcium $\left(\mathrm{Ca}^{2+}\right)$ homeostasis. Mammalian IP3Ks are involved in many biological processes, including brain development, memory, learning and so on. It is widely reported that $\mathrm{Ca}^{2+}$ is a canonical second messenger in higher plants. Therefore, plant IP3K should also play a crucial role in plant development. Recently, we reported the identification of plant IP3K gene (AtIpk2 $\beta /$ AtIP3K) from Arabidopsis thaliana and its characterization. Here, we summarize the molecular cloning, biochemical properties and biological functions of IP3Ks from animal, yeast and plant. This review also discusses potential functions of IP3Ks in signaling crosstalk, inositol phosphate metabolism, gene transcriptional control and so on.
\end{abstract}

Keywords: inositol 1,4,5-trisphosphate 3-kinase (IP 3 3-kinase/IP3K), inositol polyphosphate kinase (Ipk), inositol phosphate multikinase (Ipmk), calcium $\left(\mathrm{Ca}^{2+}\right)$, signal transduction

\section{INTRODUCTION}

Inositol 1,4,5-trisphosphate $\left(\mathrm{IP}_{3}\right)$ is an important second messenger in animal cells that mediates calcium $\left(\mathrm{Ca}^{2+}\right)$ release from the endoplasmic reticulum (ER) to the cytosol [1-3]. Inositol 1,3,4,5-tetrakisphopsphate $\left(\mathrm{IP}_{4}\right)$ is another messenger responsible for mediating $\mathrm{Ca}^{2+}$ entry through plasma membrane and mobilize intracellular $\mathrm{Ca}^{2+}$ by acting synergistically with $\mathrm{IP}_{3}$ [4]. Inositol 1,4,5trisphosphate 3-kinase ( $\mathrm{IP}_{3} 3$-kinase/IP3K) phosphorylates $\mathrm{IP}_{3}$ to $\mathrm{IP}_{4}[1,5]$. Thus, IP3K plays a key role in maintaining $\mathrm{Ca}^{2+}$ homeostasis by regulating the concentrations of $\mathrm{IP}_{3}$ and $\mathrm{IP}_{4}$.

$\mathrm{IP}_{3}$ also serves as a precursor for the synthesis of other higher inositol phosphate (IP) isomers in IP metabolism $[6,7]$. These water-soluble IP isomers are involved in multiple cellular events such as modulating Ras GTPaseactivating protein [8], blocking tumor cell growth [9], regulating mRNA export [10] and so on. In addition, inositol 1,2,3,4,5,6-hexakisphosphate $\left(\mathrm{IP}_{6}\right)$ is related to human neutrophil function [11] and plant seed germination

Correspondence: Hui Jun XIA

Tel: $+86-27-68752112$

Fax: +86-27-68752112

Email: hjxia@whu.edu.cn
$[12,13]$. Yeast and Arabidopsis IP3Ks, also referred to as inositol polyphosphate kinase (Ipk) and inositol phosphate multikinase (Ipmk), recognize $\mathrm{IP}_{3}$ as substrate and add a phosphate to position 6 on the inositol ring to generate inositol 1,4,5,6-tetrakisphosphate $\left(\mathrm{I}(1,4,5,6) \mathrm{P}_{4}\right)[10,14,15]$. It is further phosphorylated by yeast and Arabidopsis IP3Ks to produce inositol 1,3,4,5,6-pentakisphosphate $\left(\mathrm{IP}_{5}\right)[10$, $14,15]$. Therefore, the physiological function of IP3K is not only regulating intracellular $\mathrm{Ca}^{2+}$ homeostasis, but also controlling IP metabolism (Fig. 1).

\section{MOLECULAR CLONING OF IP3K}

Inostiol 1,4,5-trisphosphate 3-kinase ( $\mathrm{IP}_{3}$ 3-kinase)

The first $\mathrm{IP}_{3} 3$-kinase cDNA ( $\left.\mathrm{RnIP}_{3} 3 \mathrm{~K}-\mathrm{A}\right)$ was isolated from rat brain in 1990 [16-18]. Afterwards, several cDNAs encoding $\mathrm{IP}_{3}$ 3-kinase were consequently cloned from human $\left(\mathrm{HsIP}_{3} 3 \mathrm{~K}-\mathrm{A}, \mathrm{HsIP}_{3} 3 \mathrm{~K}-\mathrm{B}, \mathrm{HsIP}_{3} 3 \mathrm{~K}-\mathrm{C}\right)$ and rat (RnIP 3 3K-B, RnIP 3 K-C) [19-23]. Rat RnIP 3 K-B is 204 amino acids longer than that of the human $\mathrm{HsIP}_{3} 3 \mathrm{~K}-\mathrm{B}$, but remaining similar to its human homologue with $93 \%$ identity in amino acids [21]. The recently identified human $\mathrm{HsIP}_{3} 3 \mathrm{~K}-\mathrm{C}$ shares a highly conserved catalytic domain with human isoforms $\mathrm{A}$ and $\mathrm{B}[22,23]$. It is about $75 \%$ identical to rat $\mathrm{RnIP}_{3} 3 \mathrm{~K}-\mathrm{C}[22,23] . \mathrm{IP}_{3}$ 3-kinase from chicken [24], nematode [25] and fruit fly [26] has also been identified. 


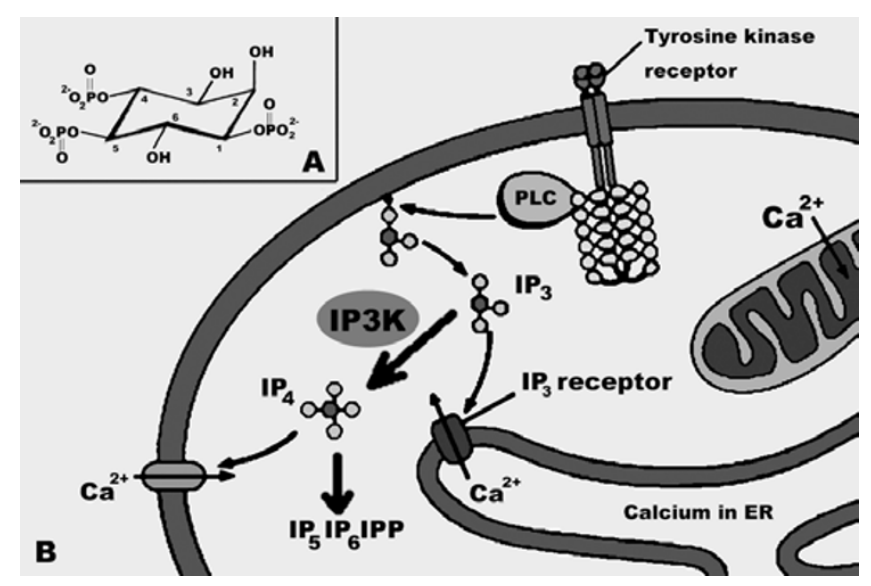

Fig. 1 IP3K function in inositol metabolism and calcium homeostasis. Panel A shows the structure of inositol 1,4,5-trisphosphate $\left(\mathrm{IP}_{3}\right)$. Panel B shows IP3K's role in phosphorylating $\mathrm{IP}_{3}$ to $\mathrm{IP}_{4}$ and $\mathrm{IP}_{5}$. IP3K regulates intracellular calcium homeostasis by controlling the balance of $\mathrm{IP}_{3}$ and $\mathrm{IP}_{4}$.

There are at least three distinct $\mathrm{IP}_{3}$ 3-kinase isoforms (A, B, and C). They are different in their molecular masses, $\mathrm{Ca}^{2+} /$ calmodulin $\left(\mathrm{Ca}^{2+} / \mathrm{CaM}\right)$ sensitivity, intracellular distribution and tissue expression $[23,27]$ (Tab. 1). Mammalian $\mathrm{IP}_{3} 3$-kinases are usually activated by $\mathrm{Ca}^{2+} / \mathrm{CaM}$ [28]. Nematode $\mathrm{IP}_{3} 3$-kinase instead lacks a consensus CaM-binding site and thus is insensitive to $\mathrm{Ca}^{2+} / \mathrm{CaM}$ [25]. There are evidences suggesting that the N-terminal sequence of $\mathrm{IP}_{3} 3$-kinases is involved in intracellular localization $[27,29]$. For example, the N-terminal 320 amino acid sequence of rat $\mathrm{RnIP}_{3} 3 \mathrm{~K}-\mathrm{B}$ is unique and is necessary for the binding of rat $\mathrm{RnIP}_{3} 3 \mathrm{~K}-\mathrm{B}$ to the cytosolic face of the ER membrane [30]. $\mathrm{IP}_{3}$ 3-kinase isoforms show tissue specificity, such as rat $\mathrm{RnIP}_{3} 3 \mathrm{~K}-\mathrm{A}$ is specifically expressed in brain and testes, whereas rat $\mathrm{RnIP}_{3} 3 \mathrm{~K}-\mathrm{B}$ is predominantly expressed in lung and also in thymus, heart, testes and brain [29]. Such specified distribution and expression pattern of $\mathrm{IP}_{3} 3$-kinases may contribute to their various physiological functions. However, all these $\mathrm{IP}_{3} 3-$ kinases seem to have strict biochemical activity in phosphorylating $\mathrm{IP}_{3}$ to $\mathrm{IP}_{4}$ [25-27].

\section{Inositol phosphate multikinase (Ipmk)/inositol polyphosphate kinase (Ipk)}

Inositol phosphate multikinase (Ipmk) is widely distributed in the kingdoms of animal, plant and yeast [31]. The first identified Ipmk cDNA (also called Ipk2) was from yeast $[10,14]$. Yeast Ipk2/Ipmk/IP3K is a dual-specificity $\mathrm{IP}_{3} / \mathrm{IP}_{4} 6 / 3$-kinase and identical to Arg82/ArgRIII which is an indispensable component of ArgR-Mcm 1 transcriptional complex [10]. The ArgR-Mcm1 complex functions in transcriptional control of genes involved in arginine metabolism [32, 33]. However, the inositol phosphorylation activity Arg82 is not required for the transcriptional regulation [34]. We previously reported the molecular cloning and characterization of a plant IP3K gene (AtIpk2 $3 /$ AtIP3K) from Arabidopsis [15]. The amino acid sequence of AtIpk $2 \beta$ shares $73 \%$ identity and $84 \%$ similarity to that of a second Arabidopsis IP3K, AtIpk2 $\alpha$. [15, 35]. Similar to yeast IP3K, Arabidopsis IP3K is also a dual-specificity $6 / 3$-kinase $[15,35]$. York and his colleagues reported that

Tab. 1 Biochemical and molecular characteristics of IP3K isoforms from human, rat and Arabidopsis.

\begin{tabular}{|c|c|c|c|c|c|c|}
\hline Organism & Isoforms & $\begin{array}{l}\text { Molecular } \\
\text { mass }(\mathrm{kD})\end{array}$ & $\begin{array}{l}\text { Amino } \\
\text { acids (aa) }\end{array}$ & $\begin{array}{l}\mathrm{Ca}^{2+} / \mathrm{CaM} \\
\text { sensitivity }\end{array}$ & $\begin{array}{l}\text { Intracellular } \\
\text { distribution }\end{array}$ & Tissue expression \\
\hline \multirow[t]{3}{*}{ Human } & $\mathrm{HsIP}_{3} 3 \mathrm{~K}-\mathrm{A}$ & 50.0 & 461 & $2 \sim 3$ fold & \multirow{4}{*}{\multicolumn{2}{|c|}{$\begin{array}{l}\text { Cytoskeleton } \\
\text { Plasma membrane, } \\
\text { cytoskeleton and ER } \\
\text { Cytoplasmic }\end{array}$}} \\
\hline & $\mathrm{HsIP}_{3} 3 \mathrm{~K}-\mathrm{B}$ & 53.5 & 472 & $7 \sim 8$ fold & & \\
\hline & $\mathrm{HsIP}_{3} 3 \mathrm{~K}-\mathrm{C}$ & 75.2 & 684 & $\begin{array}{l}\mathrm{Ca}^{2+} \text { decrease } \\
\mathrm{CaM} \text { reverse }\end{array}$ & & \\
\hline \multirow[t]{3}{*}{ Rat } & $\mathrm{RnIP}_{3} 3 \mathrm{~K}-\mathrm{A}$ & 50.9 & 459 & $3 \sim 6$ fold & & \\
\hline & $\mathrm{RnIP}_{3} 3 \mathrm{~K}-\mathrm{B}$ & 74.0 & 673 & & & $\begin{array}{l}\text { Brain and Testes } \\
\text { Lung, thymus, heart, testes, } \\
\text { and brain }\end{array}$ \\
\hline & $\mathrm{RnIP}_{3} 3 \mathrm{~K}-\mathrm{C}$ & 74.5 & 678 & & & $\begin{array}{l}\text { Heart, brain, testes, tongue } \\
\text { epithelium }\end{array}$ \\
\hline \multirow[t]{2}{*}{ Arabidopsis } & AtIpk $2 \alpha$ & 31.9 & 286 & Not affected & & $\begin{array}{l}\text { Leaf, stem, root, flower, } \\
\text { silique }\end{array}$ \\
\hline & AtIpk $2 \beta$ & 33.5 & 300 & Not affected & & $\begin{array}{l}\text { Pollen, flower, root, } \\
\text { mesophyll cells }\end{array}$ \\
\hline
\end{tabular}


Arabidopsis IP3K has a novel 5-kinase activity to phosphate $\mathrm{I}(1,3,4,6) \mathrm{P}_{4}$ to generate $\mathrm{I}(1,2,3,4,6) \mathrm{P}_{5}[35]$. Identified Ipmks include those from human [36] and rat [37].

Human Ipmk is very similar to rat Ipmk with $84 \%$ amino acid sequence identity [31]. Arabidopsis IP3K and yeast IP3K are less conserved in the Ipmk superfamily with $25 \%$ and $16 \%$ amino acid sequence identity to human Ipmk respectively [31]. Within the catalytic domain of Ipmks family, mammalian homologues share $25-33 \%$ and $42-54 \%$ identity to yeast and Arabidopsis IP3Ks respectively. Ipmks have conserved IP-binding consensus sequence and ATPbinding site in their catalytic domain [31]. Fig. 2 depicts a schematic alignment of IP3Ks from rat, human, yeast and Arabidopsis. The expression patterns of Ipmks are different: rat Ipmk is highly expressed in kidney and brain [37], whereas human Ipmk is ubiquitously expressed [36]. Although Arabidopsis IP3K has similar transcript level in flower, root, stem, and leave [15], its activity is detected only in mature pollens, but not in immature pollen grains [15].

\section{IP3K STRUCTURE}

There are two major functional domains in mammalian IP3Ks: a highly conserved C-terminal catalytic domain and a divergent $\mathrm{N}$-terminal regulatory domain. The structure of mammalian IP3Ks catalytic core (residues $185-459$ of rat $\mathrm{RnIP}_{3} 3 \mathrm{~K}-\mathrm{A}$ ) consists of two domains: a large $\alpha / \beta$-class structure and a small $\alpha$-helical structure [38-40]. The $\alpha / \beta-$ class structure has two lobes that are necessary for ATP/ $\mathrm{Mg}^{2+}$-binding with critical residues Lys-197, Lys-262, Arg317 and Asp-414, whereas the small $\alpha$-helical structure is responsible for $\mathrm{IP}_{3}$-binding in dependence of a 35 amino acid sequence of Arg-276 to Lys-303 [39, 40-43]. Many hydrophobic residues of the large domain also participate in ATP binding [39]. The $\mathrm{IP}_{3}$-binding core is inserted between two lobes of the large domain acting together during ATP binding and phosphate transfer [43, 44]. Sequence alignment of IP3Ks shows that consensus sequence PxxDDxKxG is a highly conserved motif for substrate binding [31]. However, the small helix domain is absent in mammalian Ipmks, yeast and Arabidopsis IP3Ks [39]. This may explain the substrate specificity of $\mathrm{IP}_{3} 3-$ kinase and Ipmk from the structure level. Motif $[\mathrm{L} / \mathrm{M}][\mathrm{I} / \mathrm{V}]$ $\mathrm{D}[\mathrm{F} / \mathrm{L}][\mathrm{A} / \mathrm{G}][\mathrm{H} / \mathrm{K}]$ is also considered as a putative ATP/ $\mathrm{Mg}^{2+}$-binding sequence in Ipmks [37]. Furthermore Saiardi et al identified a new domain designated "SSLL" in rat Ipmk [37]. The SSLL-like motif is also conserved within other IP3Ks [31, 37]. Mutational analysis shows that loss of this motif may impair catalysis activity of IP3Ks [37].

Intracellular localization of IP3Ks is contributed by special domains. A novel N-terminal 66 amino acid sequence in rat $\mathrm{RnIP}_{3} 3 \mathrm{~K}-\mathrm{A}$ is involved in $\mathrm{F}$-actin binding [45]. A

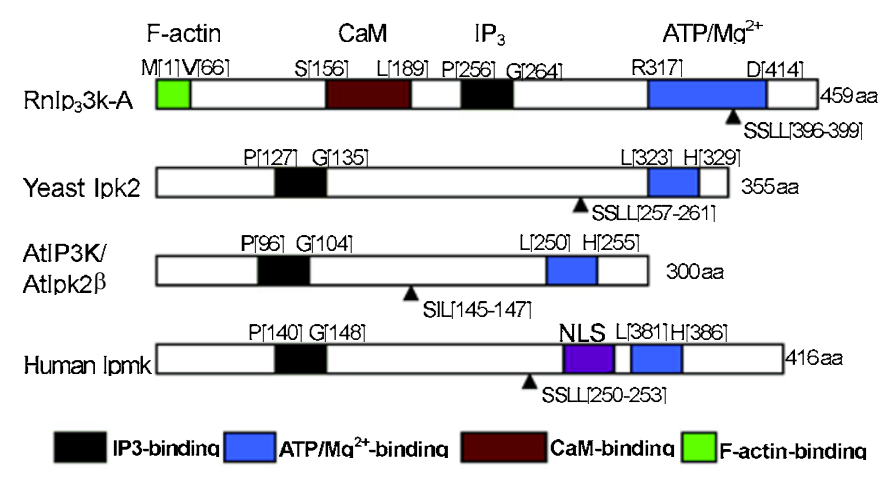

Fig. 2 The structure of IP3K family. The various conserved domains are marked by colored boxes. The dark green box and the blue box show $\mathrm{IP}_{3}$-binding domain and $\mathrm{ATP} / \mathrm{Mg}^{2+}$-binding domain, respectively. The red box represents CaM-binding domain. The light green box shows F-actin-binding domain. The SSLL-like motif is also conserved in IP3K. A nucleus localization signal (NLS) is represented by the purple box.

similar actin-binding domain was also identified in rat $\mathrm{RnIP}_{3} 3 \mathrm{~K}-\mathrm{B}$ [46]. Rat RnIP 3 KK-B can bind to ER membrane with high-affinity, depending upon conformation, and protein-protein interaction [30]. Soriano and Banting hypothesized that the N-terminus of $\mathrm{RnIP}_{3} 3 \mathrm{~K}-\mathrm{B}$ was only required for the binding of the enzyme to the ER in proximity of the $\mathrm{IP}_{3}$ receptor [30]. This N-terminal 320 amino acids are unique for the rat IP3K isoform $\mathrm{B}$, which contributes to its subcellular localization to the ER [30]. Rat $\mathrm{RnIP}_{3} 3 \mathrm{~K}-\mathrm{C}$ is exclusively cytoplasmic but shuttles between cytoplasm and the nucleus [23]. A nuclear export signal (NES) has been identified at its N-terminus [23]. A similar nuclear localization signal (NLS) has also been discovered in human Ipmk [47]. Both yeast and Arabidopsis IP3Ks are nucleus localized $[10,15]$. However, no obvious NSL can be found through sequence alignment [15]. Different domains are presented in Fig. 2.

\section{IP3K REGULATORS}

\section{$\mathrm{Ca}^{2+} / \mathrm{CaM}$}

Mammalian IP3Ks can be activated by $\mathrm{CaM}$ in a $\mathrm{Ca}^{2+}$ dependent manner to different degrees. $\mathrm{CaM}$ recognizes sequences which contain amphiphilic $\alpha$-helices with clusters of positively charged and hydrophobic amino acids [38]. Sequence from Ser-156 to Leu-189 together with site Trp- 165 in rat IP $33 \mathrm{~K}-\mathrm{A}$ is required for CaM binding and the enzyme activation $[38,48,49]$. The level of stimulation appears to be cell-, tissue- and isoform-specific $[27,50]$ (Tab. 1). Up to 20 -fold of increase in IP3Ks enzymatic activities by $\mathrm{Ca}^{2+} / \mathrm{CaM}$ can be observed in a in vitro assay using purified IP3Ks from rat [17, 51], pig 
and human $[29,52,53]$. However, IP3Ks from nematode [25], Arabidopsis [15] and yeast [10] lack the consensus CaM-binding sites and thus are insensitive to $\mathrm{Ca}^{2+} / \mathrm{CaM}$.

\section{PKA, PKC and CaMKII}

Mammalian IP3Ks are substrates of camp-dependent kinase (PKA), protein kinase $\mathrm{C}$ (PKC) and $\mathrm{Ca}^{2+} / \mathrm{CaM}$ denpendent kinase II (CaMKII). PKA can stimulate IP3K activity. In contrast, $\mathrm{PKC}$ is a negative regulator of IP3K [54]. Ser-175 on $\mathrm{RnIP}_{3} 3 \mathrm{~K}-\mathrm{A}$ is the phosphorylation site for PKC, and Ser-109 for both PKC and PKA [28]. Simultaneous phosphorylation of Ser-109 and Ser-175 leads to inactivation of the enzyme, whereas a single phosphorylation at Ser-109 activates it, suggesting that Ser-175 is probably the inhibitory phosphorylation site [28]. CaMKII is also a positive regulator of IP3K [55]. Thr-311 of human $\mathrm{HsIP}_{3} 3 \mathrm{~K}-\mathrm{A}$ is a CaMKII phosphorylation site. CaMKII can stimulate enzyme activity by $8 \sim 10$-fold $[54,55]$. The phosphorylation level of IP3K varies depending upon $\mathrm{Ca}^{2+} / \mathrm{CaM}-$ sensitivity and different isoforms [55]. To date, it is not clear whether Ipmk is sensitive to PKC, PKA, CaMKII. But Arabidopsis IP3K can be phosphorylated by PKC in vitro [15]. Further experiments are needed to elucidate how the activity of Arabidopsis IP3K is regulated.

\section{Other regulators}

Mammalian IP3Ks activity can be stimulated by $12-\mathrm{O}-$ tetradecanoylphorbol-13-acetate (TPA) in the presence of cAMP [56-58]. Protein stability is also involved such as mammalian IP3Ks are very sensitive to calpains [59].
Pp60v-src kinase can also increase IP3K activity, although the src-phosphorylation site in IP3K has not been identified yet [60].

\section{IP3K FUNCTIONS}

IP3Ks are involved in inositol signaling pathway, calcium signal transduction, brain development, stress responses and gene transcription (Fig. 3).

\section{Inositol signaling pathway}

Mammalian IP3Ks mainly phosphorylate $\mathrm{IP}_{3}$ to $\mathrm{IP}_{4}$ to provide precursors for synthesis of higher IPs [5, 31]. Yeast and Arabidopsis IP3Ks participate additional pathway in IP metabolism $[10,15]$. In yeast, there is a subdivision of lipid-dependent pathway for $\mathrm{IP}_{6}$ synthesis [10]. IP3K phosphorylates $\mathrm{IP}_{3}$ stepwise at the D-6 and D-3 positions to generate $\mathrm{IP}_{5}$ or as a minor pathway to phosphorylate $\mathrm{IP}_{3}$ to bring about $\mathrm{IP}_{4}[10,14]$. There is evidence showing that expansion of an $\mathrm{IP}_{3}$ pool could lead to increases of $\mathrm{IP}_{4}, \mathrm{IP}_{5}$ and $\mathrm{IP}_{6}$ levels via Ipmk [61]. Thus, in higher eukaryotes Ipmk, but not $\mathrm{IP}_{3}$ 3-kinase, may be the main contributor for $\mathrm{IP}_{5}$ and $\mathrm{IP}_{6}$ syntheses [61]. Plant react in a similar way. Maize IP3K ( $\mathrm{ZmIpk})$ is responsible for $\mathrm{IP}_{6}$ biosynthesis in developing maize seed [62]. Arabidopsis IP3K has 6-/3-kinase activity and can phosphorylate $\mathrm{IP}_{3}$ to give rise to $\mathrm{IP}_{5}[15,35]$. Besides Arabidopsis IP3K exhibits a novel 5-kinase activity to produce $\mathrm{IP}_{5}$ from $\mathrm{I}(1,3,4,6) \mathrm{P}_{4}[35]$. The 5-kinase activity has also been detected in human and Drosophila Ipmks [36, 61], which

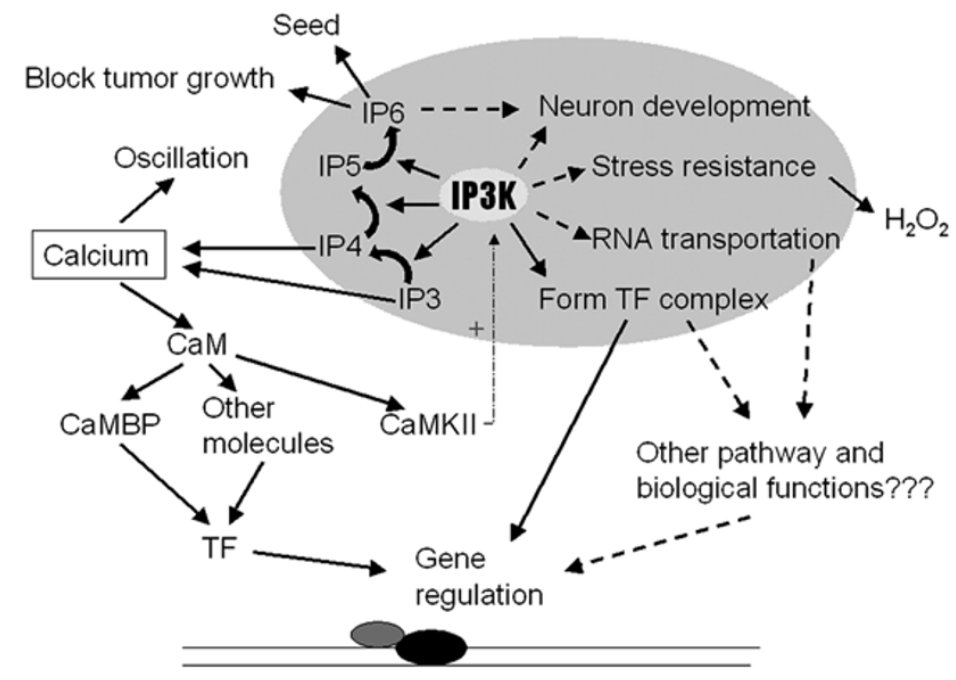

Fig. 3 The network of IP3K functions. 
is especially important for fruit flies since no $\mathrm{IP}_{3} 5-/ 6$ kinase can be found in this animal. Human Ipmk can also phosphorylate inositol 4,5-biphosphate $\left(\mathrm{IP}_{2}\right)$ to generate to $\mathrm{IP}_{3}$ and can make pyrophosphate disphosphoinositolP tetrakisphosphate $\left(\mathrm{PP}-\mathrm{IP}_{4}\right)$ from $\mathrm{IP}_{5}[36]$.

\section{Calcium signal transduction}

$\mathrm{IP}_{3}$ and $\mathrm{IP}_{4}$ regulate $\mathrm{Ca}^{2+}$ mobilization synergistically [2, 4]. Increase of IP3K activity may reduce cellular $\mathrm{IP}_{3}$ concentration and correspondingly terminate $\mathrm{IP}_{3}$ action. The function of $\mathrm{IP}_{4}$ is implicated in promoting $\mathrm{Ca}^{2+}$ entry from extracellular space [4]. Evidence shows that $\mathrm{IP}_{4}$ can activate a protein with ras- and rap-GAP activity and finally inactivate the $G$ protein [30]. This indicates that $\mathrm{IP}_{4}$ regulates $\mathrm{Ca}^{2+}$ influx in a GTP-dependent way, which potentially links the $\mathrm{IP}_{3}$ signaling pathway to GTP-regulated signaling mechanisms [30]. $\mathrm{IP}_{4}$ is demonstrated to be a common regulator in $\mathrm{Ca}^{2+}$ homeostasis [63]. A complete inhibition of IP3K activity in Hela cells by adriamycin or by IP3Kspecific antibody blocked $\mathrm{Ca}^{2+}$ oscillations, whereas a partial inhibition caused a significant reduction in oscillations frequency [63]. Taken together, IP3K activity is related to the levels of $\mathrm{IP}_{3}$ and $\mathrm{IP}_{4}$ and subsequently to $\mathrm{Ca}^{2+}$ oscillations (Fig. 3). However, it remains unknown whether yeast and Arabidopsis IP3Ks are involved in regulation of $\mathrm{Ca}^{2+}$ oscillations. Recombinant yeast IP3K mainly phosphorylates $\mathrm{IP}_{3}$ to give rise $\mathrm{I}(1,4,5,6) \mathrm{P}_{4}[10,35]$. However, $\mathrm{I}(1$, $4,5,6) \mathrm{P}_{4}$ is not as efficient as $\mathrm{IP}_{4}$ in $\mathrm{Ca}^{2+}$ influx. Yeast IP3K thus may not be relevant to $\mathrm{Ca}^{2+}$ oscillations in vivo.

\section{Brain development, memory and learning}

Rat and human IP3Ks may be involved in brain development, memory and learning. Rat IP3K activity is low at birth and reaches approximately $50 \%$ of adult levels [64]. Rat IP3K activities are the highest in the hippocampal CA1 pyramidal neurons, dentate gyrus granule cells, and cerebellar purkinje cells $[64,65]$. On the other hand, low activities were found in cerebellar granule cells, thalamus, hypothalamus, brainstem, spinal cord, and white matter tracts $[64,65]$. The expression pattern of human $H_{s} I P_{3} 3 K-A$ is similar to that of rat $\operatorname{RnIP}_{3} 3 K-A$. Human $\mathrm{HsIP}_{3} 3 \mathrm{~K}-\mathrm{B}$ is predominantly present in astrocytes $[66,67]$. The distribution of IP3Ks in rat and human brain suggests that IP3K might be involved in brain development and in memory process [68]. Spatial learning training leads to the increase of rat $\mathrm{RnIP}_{3} 3 \mathrm{~K}-\mathrm{A}$ level [69], suggesting a possible role of rat $\mathrm{RnIP}_{3} 3 \mathrm{~K}-\mathrm{A}$ in spatial learning [69].

\section{Stress responses}

Interestingly, a Drosophila IP3K gene (D-IP3K1) appears to be oxidative damage resistant [26]. Ubiquitous overexpression of $D-I P 3 \mathrm{~K} 1$ confers resistance of flies to $\mathrm{H}_{2} \mathrm{O}_{2}$ but not to paraquat-induced oxidative stress [26]. Evidence suggests that the protective effect of $D-I P 3 K 1$ is mainly due to a reduced $\mathrm{IP}_{3}$ level and thus reduced calcium release from internal stores, rather than an increased $\mathrm{IP}_{4}$ level [26]. IP3K activity is the key player in this process [26]. In yeast, the IP3K activity has also been demonstrated to be required for resistance to salt stress, cell wall integrity and vacuolar morphogenesis [70].

\section{Gene transcription}

Yeast IP3K (Ipk2/Arg82) was identified as a regulator of arginine metabonism [10]. The complex ArgR-Mcm1 is required to ensure the coordination of gene expression in response to arginine $[10,71]$. Arg80 and $\mathrm{Mcm} 1$ are members of the MADS-box transcription factor family, whereas Arg81, a zinc cluster protein, is the sensor of arginine [72]. Three components (Arg80, Arg81 and $\mathrm{Mcm} 1$ ) are sufficient to form a complex with DNA (arginine boxes) in the presence of arginine [72]. Yeast IP3K stabilizes Mcm1 and Arg80, and facilitates their assembly into a multimeric complex [72]. A poly-Asp domain between amino acid residues 282-303 of yeast IP3K is essential for stability of $\operatorname{Arg} 80$ and Mcm1 [73]. It was argued that the absence of this domain leads to the failure of forming ArgRMcm1 transcriptional complex [73]. Arabidopsis IP3K has a similar function, which complements yeast Arg82/Ipk2 mutant lacking a functional ArgR-Mcm1 transcriptional complex [15]. However, no significant poly-Asp domain is found in Arabidopsis IP3K [15]. This evidence is somewhat contradicted to previous hypothesis about the role of yeast IP3K in forming transcriptional complex.

\section{Others}

$\mathrm{IP}_{4}$ can bind with high affinity to several intracellular proteins - synaptotagmin (I and II), Gap1, Btk, and centaurin- $\alpha$ - and may interact with synaptotagmin to inhibit synaptic transmission [74]. $\mathrm{IP}_{4}$ also acts as a mediator in neuronal death in the ischemic hippocampus [75]. The changes in $\mathrm{IP}_{3}$ metabolism may be correlated to critical stages of muscle development and differentiation, which suggests a possible role for IP3K in these processes [76]. Moreover, yeast IP3K is involved in cellular mRNA export from the nucleus with Ipk1 and plays a role in determining messenger RNA export from yeast nucleus [10, 77]. Recent analysis shows that Arabidopsis IP3K (AtIpk $2 \alpha$ ) is also associated with pollen germination and root growth [78].

\section{PERSPECTIVE}

\section{Signaling crosstalk}

IP3K may be a key player in integrating $\mathrm{Ca}^{2+}$ signaling, IP metabolism and other signaling pathways. In plant, $\mathrm{Ca}^{2+}$ levels are modulated by $\mathrm{IP}_{3}$ in response to various signals 
including hormones, light and abiotic stresses. For example, the addition of abscisic acid (ABA) leads to increase in endogenous $\mathrm{IP}_{3}$ levels [79]; red light elicits a rapid $\mathrm{Ca}^{2+}$ intracellular release which can be mimicked by microinjection of $\mathrm{IP}_{3}$ [80]; gravity stimulates a rapid increase of $\mathrm{IP}_{3}$ in maize [81]. However, this may not be the only way for IP3K function in many biological processes. $\mathrm{IP}_{4}, \mathrm{IP}_{5}$, and $\mathrm{IP}_{6}$ have been demonstrated functionally important $[9-13,82]$. They have recently been implicated as messengers regulating cellular processes including transcription, DNA repair and channel activity $[6,7] . \mathrm{IP}_{6}$ serves as a storage poll of IPs and mineral nutrients in seeds $[12,13]$. Thus, IP3K may also participate in controlling plant development by regulating subsequent IP signaling pathways. A new exciting function for yeast and Arabidopsis IP3Ks was found in regulation of gene expression $[10,15]$. A fully understand of the physiological function of IP3K needs a comprehensive consideration of IP3K network. IP3K may simultaneously regulate $\mathrm{Ca}^{2+}$ homeostasis, IP metabolism and gene transcription in response to external stimulus.

\section{Inositol phosphate metabolism}

Signals induced by $\mathrm{IP}_{3}$ can be terminated by two ways; either through dephosphorylation by a 5-phosphatase to give inositol 1,4-biphosphate $\left(\mathrm{IP}_{2}\right)$ or through phosphorylation by IP3K to produce $\mathrm{IP}_{4}$ [83]. Ipmk may replace $\mathrm{IP}_{3}$ 3-kinase due to their similar enzymatic activities $[10$, 35]. Cellular $\mathrm{IP}_{3}$ serves as a substrate for both $\mathrm{IP}_{3} 3$ kinase and Ipmk to form $\mathrm{IP}_{6}$ [61]. Ipmk, but not $\mathrm{IP}_{3} 3$ kinase, is the major enzyme in $\mathrm{IP}_{6}$ synthesis, whereas $\mathrm{IP}_{3} 3$ kinase mainly function in $\mathrm{IP}_{4}$ synthesis from $\mathrm{IP}_{3}$ [61]. Different from animal homologues, only two IP3K isoforms (AtIpk $2 \alpha$ and AtIpk2 $\beta$ ) were isolated from Arabidopsis $[15,35]$. The general pathway for $\mathrm{IP}_{6}$ synthesis in plant as well as in yeast has been identified as follow: $\mathrm{IP}_{3} \rightarrow \mathrm{IP}_{4} /$ $\mathrm{I}(1,4,5,6) \mathrm{P}_{4} \rightarrow \mathrm{IP}_{5} \rightarrow \mathrm{IP}_{6}$ [35]. The first two steps can be phosphorylated by yeast and plant IP3Ks [10, 15, 35]. But 3-kinase activity of yeast and Arabidopsis IP3Ks seems less active than their in vivo 6-kinase activity [10, 35]. Thus, of particular interest is the mechanism of regulating $\mathrm{Ca}^{2+}$ release and influx in plant cells. However, Arabidopsis IP3K regulating pollen tube growth under different environmental conditions is $\mathrm{Ca}^{2+}$-independent [78].

\section{Gene transcriptional control}

The crystal structure of Ipmk is not yet known. Information from mammalian IP3K catalytic domain suggests that yeast and Arabidopsis IP3Ks may interact with other molecules [39, 40]. Sun et al copurified COP9 signalsome/ CSN from calf brain with inositol 1,3,4-trisphosphate 5/ 6-kinase [84]. This kinase can phosphorylate several transcription factors (NF- $\kappa \mathrm{B}, \mathrm{c}-\mathrm{Jun}, \mathrm{p} 53$ etc, ) to avoid of degradation by the ubiquitin system [84]. Both NF- $\kappa B$ and c-Jun play important roles in brain development and anti-oxidative stress $[85,86]$. Yeast IP3K activates ArgRMcm1 complex and then drives transcription [31]. We have also demonstrated that Arabidopsis IP3K complemented ipk2 mutant yeast [15], indicating a potential function of Arabidopsis IP3K in transcription regulation.

\section{IP3K regulation}

Mammalian IP3Ks can be modulated by $\mathrm{Ca}^{2+} / \mathrm{CaM}$, PKA, $\mathrm{PKC}, \mathrm{CaMKII}$ and other regulators. However, there is little information about the mechanism. Both yeast and Arabidopsis IP3Ks lack CaM-binding sites and are insensitive to $\mathrm{Ca}^{2+}$ / $\mathrm{CaM}[10,15]$. Therefore, compared to mammalian IP3Ks, they are most regulated by different mechanisms. Our preliminary experiments suggest that Arabidopsis IP3K can be phosphorylated by PKC in vitro. Whether such phosphorylation is physiologically relevant to the regulation of Arabidopsis IP3K activity in vivo is not clear. It is important to understand the function regulation of yeast and plant IP3Ks in the near future.

\section{ACKNOWLEDGEMENTS}

This work was supported by grants from the National Natural Science Foundation of China (No. 30370142), the National Special Key Project on Functional Genomics and Biochip of China (No. 2002AA2Z1002) and the Project sponsored by the Scientific Research Foundation for the Returned Oversea Chinese Scholars, State Education Ministry. We thank Dr. Yun-Bo SHI, Dr. Bernd MUELLERROEBER, Dr. Jian-Kang ZHU and Dr. Hao YU for their critical readings of this manuscript.

\section{REFERENCES}

1 Carafoli E. Calcium signaling: a tale for all seasons. Proc Natl Acad Sci USA 2002; 99:1115-22.

2 Irvine RF. Inositol phosphates and $\mathrm{Ca}^{2+}$ entry-towards a proliferation, or a simplification? ASEB J 1992; 6:3085-91.

3 Vetter SW, Leclerc E. Novel aspects of calmodulin target recognition and activation. Eur J Biochem 2003; 270:404-14.

4 Mignery GA, Johnston PA, Sudhof TC. Mechanism of $\mathrm{Ca}^{2+}$ inhibition of inositol 1,4,5-trisphosphate $\left(\mathrm{InsP}_{3}\right)$ binding to the cerebellar $\mathrm{InsP}_{3}$ receptor. J Biol Chem 1992; 267:7450-5.

5 Berridge MJ. Inositol and calcium signalling. Nature 1993; 361: 315-25.

6 Majerus PW. Inositol phosphate biochemistry. Annu Rev Biochem 1992; 61:225-50.

7 Irvine RF, Schell MJ. Back in the water: the return of the inositol phosphates. Nat Rev Mol Cell Biol 2001; 2:327-38.

8 Cullen PJ, Hsuan JJ, Truong O, et al. Identification of a specific Ins $(1,3,4,5) \mathrm{P}_{4}$-binding protein as a member of the GAP1 family. Nature 1995; 376:527-30. 
9 Ferry S, Matsuda M, Yoshida H, Hirata M. Inositol hexakisphosphate blocks tumor cell growth by activating apoptotic machinery as well as by inhibiting the Akt/NF-kb mediated cell survival pathway. Carcinogenesis 2002; 23:2031-41.

10 Odom AR, Stahlberg A, Wente SR, York JD. A role for nuclear inositol 1,4,5-trisphosphate kinase in transcriptional control. Science 2000; 287:2026-9.

11 Eggleton P, Penhallow J, Crawford N. Priming action of inositol hexakisphosphate $\left(\operatorname{InsP}_{6}\right)$ on the stimulated respiratory burst in human neutrophils. Biochim Biophys Acta 1991; 1094:309-16.

12 Raboy V, Gerbasi P. Genetics of myo-inositol phosphate synthesis and accumulation. Subcell Biochem 1996; 26:257-85.

13 Loewus FA, Murthy PPN. myo-Inositol metabolism in plants. Plant Sci 2000; 150:1-19.

14 Saiardi A, Erdjument-Bromage H, Snowman A, Tempst P, Snyder $\mathrm{SH}$. Synthesis of diphosphoinositol pentakisphosphate by a newly identified family of higher inositol polyphosphate kinase. Curr Biol 1999; 9:23-1326.

15 Xia HJ, Brearley C, Elge S, et al. Arabidopsis inositol polyphosphate 6-/3-kinase is a nuclear protein that complements a yeast mutant lacking a functional ArgR-Mcm1 transcription complex. Plant Cell 2003; 15:449-63.

16 Choi KY, Kim HK, Lee SY, Moon KH, Sim SS, Kim JW, Chung HK, Rhee SG. Molecular cloning and expression of a complementary DNA for inositol 1,4,5-trisphosphate 3-kinase. Science 1990; 248:64-6.

17 Takazawa K, Lemos M, Delvaux A, et al. Rat brain inositol 1,4, 5-trisphosphate 3-kinase. $\mathrm{Ca}^{2+}$-sensitivity, purification and antibody production. Biochem J 1990; 268:213-7.

18 Takazawa K, Vandekerckhove J, Dumont JE, Erneux C. Cloning and expression in Escherichia coli of a rat brain cDNA encoding $\mathrm{a} \mathrm{Ca}^{2+} /$ calmodulin-sensitive inositol 1,4,5-trisphosphate 3-kinase. Biochem J 1990; 272:107-12.

19 Takazawa K, Perret J, Dumont JE, Erneux C. Molecular cloning and expression of a new putative inositol 1,4,5-trisphosphate 3kinase isoenzyme. Biochem J 1991; 278:883-6.

20 Takazawa K, Perret J, Dumont JE, Erneux C. Molecular cloning and expression of a human brain inositol 1,4,5-trisphosphate 3kinase. Biochem Biophys Res Commun 1991; 174:529-535.

21 Thomas S, Brake B, Luzio JP, Stanley K, Banting G. Isolation and sequence of a full-length cDNA encoding a novel rat inositol 1,4,5-trisphosphate 3-kinase. Biochim Biophys Acta 1994; 1220: 219-22.

22 Dewaste V, Pouillon V, Moreau C, et al. Cloning and expression of a cDNA encoding human inositol 1,4,5-trisphosphate 3-kinase C. Biochem J 2000; 352:343-51.

23 Nalaskowski MM, Bertsch U, Fanick W, et al. Rat inositol 1,4, 5-trisphosphate 3-kinase $\mathrm{C}$ is enzymatically specialized for basal cellular inositol trisphosphate phosphorylation and shuttles actively between nucleus and cytoplasm. J Biol Chem 2003; 278:1976576.

24 Bertsch U, Haefs M, Möller M, et al. A novel A-isoform-like inositol 1,4,5-trisphosphate 3-kinase from chicken erythrocytes exhibits alternative splicing and conservation of intron positions between vertebrates and invertebrates. Gene 1999; 228:61-71.

25 Clandinin TR, DeModena JA, Sternberg PW. Inositol trisphosphate mediates a RAS-independent response to LET-23 receptor tyrosine kinase activation in C. elegans. Cell 1998; 92: 523-33.
26 Monnier V, Girardot F, Audin W, Tricoire H. Control of oxidative stress resistance by $\mathrm{IP}_{3}$ kinase in Drosophila melanogaster. Free Radic Biol Med 2002; 33:1250-9.

27 Dewaste V, Moreau C, De Smedt F, et al. The three isoenzymes of human inositol-1,4,5-trisphosphate 3-kinase show specific intracellular localization but comparable $\mathrm{Ca}^{2+}$ responses on transfection in COS-7 cells. Biochem J 2003; 374:41-9.

$28 \mathrm{Sim}$ SS, Kim JW, Rhee SG. Regulation of D-myo-inositol 1,4,5trisphosphate 3-kinase by cAMP- dependent protein kinase and protein kinase C. J Biol Chem 1990; 265:10367-72.

29 Vanweyenberg V, Communi D, D'Santos CS, Erneux C. Tissueand cell-specific expression of $\operatorname{Ins}(1,4,5) \mathrm{P}_{3}$ 3-kinase isoenzymes. Biochem J 1995; 306:429-35.

30 Soriano S, Banting G. Possible roles of inositol 1,4,5-trisphosphate 3-kinase B in calcium homeostasis. FEBS lett 1997; 403:1-4.

31 Shears SB. How versatile are inositol phosphate kinases? Biochem J 2004; 377:265-80.

32 Dubois E, Messenguy F. Pleiotropic function of ArgRIIIp (Arg82p), one of the regulators of arginine metabolism in Saccharomyces cerevisiae. Role in expression of cell-type-specific genes. Mol Gen Genet 1994; 243:315-24.

33 Bercy J, Bubios E, Messenguy F. Regulation of arginine metabolism in Saccharomyces cerevisiae: expression of three ARGR regulatory genes. Gene 1987; 55:277-85.

34 Dubois E, Dewaste V, Erneux C, Messenguy F. Inositol polyphosphate kinase activity of $\operatorname{Arg} 82 / \operatorname{ArgRIII}$ is not required for the regulation of the arginine metabolism in yeast. FEBS Lett 2000; 486:300-4.

35 Stevenson-Paulik J, Odom AR, York JD. Molecular and biochemical characterization of two plant inositol polyphosphate 6-/3-/5-kinases. J Biol Chem 2002; 277:42711-8.

36 Chang SC, Miller AL, Feng Y, Wente SR, Majerus PW. The human homolog of the rat inositol phosphate multikinase is an inositol 1,3,4,6-tetrakisphosphate 5-kinase. J Biol Chem 2002; 277:43836-43.

37 Saiardi A, Nagata E, Luo HR, et al. Mammalian inositol polyphosphate multikinase synthesizes inositol 1,4,5-trisphosphate and an inositol pyrophosphate. Proc Natl Acad Sci USA 2001; 98:2306-11.

38 Takazawa K, Erneux C. Identification of residues essential for catalysis and binding of calmodulin in rat brain inositol 1,4,5trisphosphate 3-kinase. Biochem J 1991; 280:125-9.

39 Miller GJ, Hurley JH. Crystal structure of the catalytic core of inositol 1,4,5-trisphosphate 3-kinase. Mol Cell 2004; 15:703-11.

40 Gonzalez B, Schell MJ, Letcher A, et al. Structure of a human inositol 1,4,5-trisphosphate 3-kinase: substrate binding reveals why it is not a phosphoinositide 3-kinase. Mol Cell 2004; 15: 689-701.

41 Communi D, Takazawa K, Erneux C. Lys-197 and Asp-414 are critical residues for binding of ATP $/ \mathrm{Mg}^{2+}$ by rat brain inositol 1, 4,5-trisphosphate 3-kinase. Biochem J 1993; 291:811-6.

42 Communi D, Lecocq R, Vanweyenberg V, Erneux C. Active site labeling of inositol 1,4,5-trisphosphate 3-kinase A by phenylglyoxal. Biochem J 1995; 310:109-15.

43 Togashi S, Takazawa K, Endo T, Erneux C, Onaya T. Structural identification of the myo-inositol 1,4,5-trisphosphate-binding domain in rat brain inositol 1,4,5-trisphosphate 3-kinase. Biochem J 1997; 326:221-5.

44 Bertsch U, Deschermeier C, Fanick W, et al. The second messen- 
ger binding site of inositol 1,4,5-trisphosphate 3-kinase is centered in the catalytic domain and related to the inositol trisphosphate receptor site. J Biol Chem 2000; 275:1557-64.

45 Schell MJ, Erneux C, Irvine RF. Inositol 1,4,5-trisphosphate 3kinase associates with $\mathrm{F}$-actin and dendritic spines via its $\mathrm{N}$ terminus. J Biol Chem 2001; 276:37537-46.

46 Brehm MA, Schreiber I, Bertsch U, Wegner A, Mayr GW. Identification of the actin-binding domain of $\operatorname{Ins}(1,4,5) \mathrm{P}_{3} 3$-kinase isoform B (IP3K-B). Biochem J 2004; 382:353-62.

47 Nalaskowski MM, Deschemeier C, Fanick W, Mayr G W. The human homologue of yeast ArgRIII is an inositol phosphate multikinase with predominantly nuclear localization. Biochem J 2002; 266:549-56.

48 Erneux C, Moreau C, Vandermeers A, Takazawa K. Interaction of calmodulin with a putative calmodulin-binding domain of inositol 1,4,5-trisphosphate 3-kinase. Effects of synthetic peptides and site-directed mutagenesis of Trp165. Eur J Biochem 1993; 214:497-501.

49 Yamaguchi K, Hirata M, Kuriyama H. Calmodulin activates inositol 1,4,5-trisphosphate 3-kinase activity in pig aortic smooth muscle. Biochem J 1987; 244:787-91.

50 Dewaste V, Roymans D, Moreau C, Erneux C. Cloning and expression of a full-length cDNA encoding human inositol 1,4,5trisphosphate 3-kinase B. Biochem Biophys Res Commun 2002; 291:400-5.

51 Conigrave A, Patwardhan A, Broomhead L, Roufogalis B. A purification strategy for inositol 1,4,5-trisphosphate 3-kinase from rat liver based upon heparin interaction chromatography. Cell Signal 1992; 4:303-12.

52 Lin A, Wallace RW, Barnes S. Purification and properties of a human platelet inositol 1,4,5-trisphosphate 3-kinase. Arch Biochem Biophys 1993; 303:412-20.

53 Woodring PJ and James C. Garrison. Expression, purification, and regulation of two isoforms of the inositol 1,4,5-trisphosphate 3-kinase. J Biol Chem 1997; 272:30447-54.

54 Lin AN, Barnes S, Wallace RW. Phosphorylation by protein kinase $\mathrm{C}$ inactivates an inositol 1,4,5-trisphosphate 3-kinase purified from human platelets. Biochem Biophys Res Commun 1990; 170:1371-6.

55 Communi D, Vanweyenberg V, Erneux C. D-myo-inositol 1,4,5trisphosphate 3-kinase $\mathrm{A}$ is activated by receptor activation through a calcium: calmodulin-dependent protein kinase II phosphorylation mechanism. Embo J 1997; 16:1943-52.

56 Biden TJ, Wollheim CB. $\mathrm{Ca}^{2+}$ regulates the inositol tris/ tetrakisphosphate pathway in intact and broken preparations of insulin-secreting RINm5F cells. J Biol Chem 1986; 261:11931-4.

57 Biden TJ, Altin JG, Karjalainen A, Bygrave FL. Stimulation of hepatic inositol 1,4,5-trisphosphate kinase activity by $\mathrm{Ca}^{2+}$-dependent and -independent mechanisms. Biochem J 1988; 256: 697-701.

58 Imboden JB, Pattison G. Regulation of inositol 1,4,5trisphosphate kinase activity after stimulation of human $\mathrm{T}$ cell antigen receptor. J Clin Invest 1987; 79:1538-41.

59 Lee SY, Sim SS, Kim JW, et al. Purification and properties of Dmyo-inositol 1,4,5-trisphosphate 3- kinase from rat brain. Susceptibility to calpain. J Biol Chem 1990; 265:9434-40.

60 Johnson RM, Wasilenko WJ, Mattingly RR, Weber MJ, Garrison JC. Fibroblasts transformed with v-src show enhanced formation of an inositol tetrakisphosphate. Science 1989; 246:
121-4.

61 Seeds AM, Sandquist JC, Spana ER, York JD. A molecular basis for inositol polyphosphate synthesis in Drosophila melanogaster. J Biol Chem 2004; 279:47222-32.

62 Shi J, Wang H, Wu Y, Hazebroek J, et al. The maize low-phytic acid mutant lpa 2 is caused by mutation in an inositol phosphate kinase gene. Plant Physiol 2003; 131:507-15.

63 Zhu DM, Tekle E, Huang CY, Chock PB. Inositol tetrakisphosphate as a frequency regulator in calcium oscillations in HeLa cells. J Biol Chem 2000; 275:6063-6.

64 Mailleux P, Takazawa K, Erneux C, Vanderhaeghen JJ. Inositol 1,4,5-trisphosphate 3-kinase mRNA: high levels in the rat hippocampal CA1 pyramidal and dentate gyrus granule cells and in cerebellar Purkinje cells. J Neurochem 1991; 56:345-7.

65 Heacock AM, Seguin EB, Agranoff BW. Developmental and regional studies of the metabolism of inositol 1,4,5-trisphosphate in rat brain. J Neurochem 1990; 54:1405-11.

66 Mailleux P, Takazawa K, Albala N, Erneux C, Vanderhaeghen JJ. Comparison of neuronal inositol 1,4,5-trisphosphate 3-kinase and receptor mRNA distributions in the human brain using in situ hybridization histochemistry. Neurosci Lett 1992; 137:6971.

67 Mailleux P, Takazawa K, Albala N, Erneux C, Vanderhaeghen JJ. Astrocytic localization of the messenger RNA encoding the isoenzyme B of inositol $(1,4,5) \mathrm{P}_{3} 3$-kinase in the human brain. Neurosci Lett 1992; 148:177-80.

68 Mailleux P, Takazawa K, Erneux C, Vanderhaeghen JJ. Inositol 1,4,5-trisphosphate 3-kinase distribution in the rat brain. High levels in the hippocampal CA1 pyramidal and cerebellar Purkinje cells suggest its involvement in some memory processes. Brain Res 1991; 539:203-10.

69 Kim IH, Park SK, Sun W, et al. Spatial learning enhances the expression of inositol 1,4,5-trisphosphate 3-kinase A in the hippocampal formation of rat. Brain Res Mol Brain Res 2004; 124: $12-9$.

70 Dubois E, Scherens B, Vierendeels F, et al. In Saccharomyces cerevisiae, the inositol polyphosphate kinase activity, and vacuolar morphogenesis. J Biol Chem 2002; 277:23755-63.

71 York JD, Odom AR, Murphy R, Ives EB, Wente SR. A phospholipase C-dependent inositol polyphosphate kinase pathway required for efficient messenger RNA export. Science 1999; 285: 96-100.

72 El Alami M, Messenguy F, Scherens B, Dubois E. Arg82p is a bifunctional protein whose inositol phosphate kinase activity is essential for nitrogen and $\mathrm{PHO}$ gene expression but not for Mcmlp chaperoning in yeast. Mol. Microbio 2003; 49:457-68.

73 Saiardi A, Caffrey JJ, Snyder SH, Shears SB. Inositol polyphosphate multikinase (ArgRIII) determines nuclear mRNA export in Saccharomyces cerevisiae. FEBS Lett 2000; 468:2832.

74 Sims CE, Nancy L. Allbritton metabolism of inositol 1,4,5trisphosphate and inositol 1,3,4,5-tetrakisphosphate by the oocytes of Xenopus laevis. J Biol Chem 1998; 273:4052-8.

75 Tsubokawa H, Oguro K, Robinson HP, et al. Inositol 1,3,4,5tetrakisphosphate as a mediator of neuronal death in ischemic hippocampus. Neuroscience 1994; 59:291-7.

76 Carrasco MA, Marambio P, Jaimovich E. Changes in $\mathrm{IP}_{3}$ metabolism during skeletal muscle development in vivo and in vitro. Comp Biochem Physiol B Biochem Mol Bio 1997; 116:173-81. 
77 Amar N, Messenguy F, Bakkoury ME, Dubois E. ArgRII, a component of the ArgR-Mcml complex involved in the control of arginine metabolism in Saccharomyces cerevisiae, is the sensor of Arginine. Mol Cell Biol 2000; 20:2087-97.

$78 \mathrm{Xu}$ J, Brearley CA, Lin WH, et al. A role of Arabidopsis inositol polyphosphate kinase AtIpk $2 \alpha$, in pollen germination and root growth. Plant Physiol 2005; 137:94-103.

79 Lee Y, Choi Y, Suh S, et al. Abscisic acid-induced phosphoinositide turnover in guard cell protoplasts of Vicia faba. Plant Physiol 1996; 110:987-96.

80 Shacklock PS, Read ND, Trewavas AJ. Cytosolic free calcium mediates red light-induced photomorphogenesis. Nature 1992; 358:753-55.

81 Perera IY, Heilmann I, Boss WF. Transient and sustained increases in inositol 1,4,5-trisphosphate precede the differential growth response in gravistimulated Maize pulvini. Proc Natl Acad Sci USA 1999; 96:5838-43.

82 Pouillon V, Hascakova-Bartova R, Pajak B, et al. Inositol 1,3,4, 5-tetrakisphosphate is essential for T lymphocyte development. Nat Immunol 2003; 4:1136-43.

83 Erneux C, Govaerts C, Communi D, Pesesse X. The diversity and possible functions of the inositol 5-polyphosphatases. Biochim Biophys Acta 1998; 1436:185-99.

84 Sun Y, Wilson MP, Majerus PW. Inositol 1,3,4-Trisphosphate 5/6-Kinase Associates with the COP9 Signalosome by Binding to CSN1. J Bio Chem 2002; 277:45759-64.

85 Hiscott J, Kwon H, Génin P. Hostile takeovers: viral appropriation of the NF- $\kappa B$ pathway. J Clin Invest 2001; 107:143-51.

86 Rodríguez-Iturbe B, Vaziri ND, Herrera-Acosta J, Johnson RJ. Oxidative stress, renal infiltration of immune cells, and salt-sensitive hypertension: all for one and one for all. Am J Physiol Renal Physiol 2004; 286:606-16.

87 El Backkoury M, Dubois E, Messenguy F. Recruiment of yeast MADS-box proteins, ArgRI and Mcm1 by the pleitropic factor ArgRIII is required for their stability. Mol. Microbio 2000; 35: 15-31. 